\title{
Enhanced Catalytic Performance through In- Situ Encapsulation of Ultrafine Ru Clusters within a High-Aluminum Zeolite
}

\author{
Jiangqian Yang, ${ }^{\text {at }}$ Ying He, ${ }^{\text {at }}$ Jiang He, ${ }^{b, c}$ Yuanshuai Liu, ${ }^{d, e}$ Huawei Geng, ${ }^{e}$
}

Shaohua Chen, ${ }^{f}$ Lu Lin, ${ }^{b}$ Meng Liu, ${ }^{a}$ Tiehong Chen, ${ }^{f}$ Qike Jiang,,$g$ Bert M.

Weckhuysen, ${ }^{* d}$ Wenhao Luo ${ }^{* b}$ and Zhijie $W u^{* a}$

${ }^{a}$ State Key Laboratory of Heavy Oil Processing and the Key Laboratory of Catalysis of CNPC, China University of Petroleum-Beijing, Fuxue Road 18, Changping, Beijing, 102249, China, E-mail: zhijiewu@ @up.edu.cn

${ }^{\mathrm{b}}$ CAS Key Laboratory of Science and Technology on Applied Catalysis, Dalian Institute of Chemical Physics, Chinese Academy of Sciences, 457 Zhongshan Road, Dalian,116023, China, E-mail: w.luo@dicp.ac.cn

c University of Chinese Academy of Sciences, Beijing 100049, China

${ }^{\mathrm{d}}$ Inorganic Chemistry and Catalysis group, Debye Institute for Nanomaterials

Science, Utrecht University, Universiteitsweg 99, 3584CG Utrecht, The Netherlands, E-mail: B.M.Weckhuysen@uu.nl 
${ }^{\mathrm{e}}$ Qingdao Institute of Bioenergy and Bioprocess Technology, Chinese Academy of Sciences, Songling Road 189, Laoshan District, Qingdao, 266101, China

${ }_{\mathrm{f}}^{\mathrm{f}}$ School of Materials Science and Engineering, Nankai University, Tianjin, 300071, China

g Dalian National Laboratory for Clean Energy, Dalian Institute of Chemical Physics, Chinese Academy of Sciences, 457 Zhongshan Road, Dalian,116023, China,

* These authors contributed equally to this work. 


\section{Experimental}

\section{Materials Synthesis}

\section{Synthesis of parent ZSM-5 and Ru@ZSM-5 zeolite}

For the synthesis of zeolite, $0.88 \mathrm{~g}$ of aluminium isopropoxide (AIP, 24 wt.\% $\mathrm{Al}_{2} \mathrm{O}_{3}$, Aldrich) was mixed with $3.0 \mathrm{~g}$ of tetrapropyl ammonium bromide (TPABr, $99 \%$, Aldrich) in $18.0 \mathrm{~g}$ of deionized water to form homogeneous aqueous solution by stirring at room temperature for 20 min. After that, $1.0 \mathrm{~g}$ and $0.9 \mathrm{~g}$ of sodium bromide $(\mathrm{NaBr}$, 99 wt.\%, Sinopharm Chemical Reagent Co., Ltd.) and sodium hydroxide (NaOH, 99 wt.\%, Sinopharm Chemical Reagent Co., Ltd.) was dissolved in the above solution by vigorous stirring at room temperature for $20 \mathrm{~min}$, respectively. Subsequently, $7.5 \mathrm{~g}$ of silica gel $\left(0.075-0.15 \mathrm{~mm}, 99\right.$ wt. $\% \mathrm{SiO}_{2}$, and $>0.4 \mathrm{~g} \mathrm{~cm}^{-3}$ bulk density, Qingdao Haiyang Chemical Co. Ltd) was directly transferred into the above solution by vigorous stirring for $1 \mathrm{~h}$ to achieve a homogeneous alumino-silicate gel with a Si/Al ratio at $\sim 30$. The as-prepared gels were transferred into a $100 \mathrm{~mL}$ stainless steel autoclave with Teflon liners for the in-situ two-stage hydrothermal synthesis. First, low temperature nucleation at $373 \mathrm{~K}$ under static conditions was proceeded for $48 \mathrm{~h}$, and then the crystallization temperature was increased to $443 \mathrm{~K}$ with $15 \mathrm{~K} / \mathrm{min}$ ramping rate and kept for $24 \mathrm{~h}$. After the crystallization, the autoclave was quenched by flowing tap water, and the solid product was separated from solution by vacuum filtration and washed with deionized water. When the $\mathrm{pH}$ value of the filtrate was around 7 , the solid 
product was transferred in a $373 \mathrm{~K}$ oven for $\sim 12 \mathrm{~h}$. The sodium type ZSM-5 zeolite was obtained by the subsequent $6 \mathrm{~h}$ calcination in air at $823 \mathrm{~K}$ (a ramping rate of $2 \mathrm{~K} / \mathrm{min}$ ) to remove the organic templates.

For the encapsulation of the Ru metal clusters (Ru@ZSM-5), $0.15 \mathrm{~g} \mathrm{RuCl}_{3}$ precursor (47 wt.\% Ru, Sinopharm Chemical Reagent Co., Ltd) was introduced into the aluminosilicate gel pre-crystallized at $373 \mathrm{~K}$ for $24 \mathrm{~h}$. After that, the crystallization temperature was increased to $443 \mathrm{~K}$ with a ramping rate of $0.25 \mathrm{~K} / \mathrm{s}$ and kept for $24 \mathrm{~h}$. The assynthesized solid product was filtered, washed with water for several times, and then dried at $373 \mathrm{~K}$ in the oven overnight, followed by calcination at $823 \mathrm{~K}$ for $6 \mathrm{~h}$. Finally, the sample was reduced by $9 \% \mathrm{H}_{2} / \mathrm{N}_{2}(300 \mathrm{~mL} / \mathrm{min})$ at $623 \mathrm{~K}$ (ramping rate: 0.0333 $\mathrm{K} / \mathrm{s}$ ) for $2 \mathrm{~h}$. Before the exposure to ambient air, all the samples were passivated under flowing $0.5 \% \mathrm{O}_{2} / \mathrm{N}_{2}(100 \mathrm{~mL} / \mathrm{min})$ for $1 \mathrm{~h}$ at $298 \mathrm{~K}$.

\section{Synthesis of Ru/ZSM-5-HT via one-step hydrothermal synthesis}

$\mathrm{Ru} / \mathrm{ZSM}-5-\mathrm{HT}$ zeolite was prepared by one-step hydrothermal synthesis using the same alumino-silicate gel composition with $\mathrm{RuCl}_{3}$ precursor of $\mathrm{Ru} @ \mathrm{ZSM}-5$ above. In a typical synthesis, the same gel was prepared and directly put in a $443 \mathrm{~K}$ oven for hydrothermal synthesis for $48 \mathrm{~h}$ without the nucleation process. The as-synthesized solid product was centrifuged, washed with water for several times, and then dried at $373 \mathrm{~K}$ in the oven overnight, followed by calcination at $823 \mathrm{~K}$ for $6 \mathrm{~h}$. Finally, the 
sample was reduced by $9 \% \mathrm{H}_{2} / \mathrm{N}_{2}$ and passivated by $0.5 \% \mathrm{O}_{2} / \mathrm{N}_{2}$ with the same procedure as Ru@ZSM-5 catalysts.

\section{Synthesis of $\mathrm{Ru} / \mathrm{ZSM}-5-\mathrm{IP}$ and $\mathrm{Ru} / \mathrm{SiO}_{2}$ via impregnation}

$\mathrm{Ru} / \mathrm{ZSM}-5$-IP was prepared by the wet-impregnation method. The required amount of $\mathrm{RuCl}_{3}$ precursor solution $(22 \mathrm{~mL})$ was prepared with deionized water at $303 \mathrm{~K}$ and $400 \mathrm{rpm}$ stirring rate. After $10 \mathrm{~min}$ of stirring, the ZSM-5 support was slowly added to the impregnation solution, with agitation speed $400 \mathrm{rpm}$ at $303 \mathrm{~K}$ for about $1 \mathrm{~h}$. Then, the temperature was raised to $358 \mathrm{~K}$ and kept at that temperature for $12 \mathrm{~h}$, allowing evaporation of the solvent at a desirable rate. The samples were dried at $373 \mathrm{~K}$ for $6 \mathrm{~h}$ and then calcined in an air flow of $300 \mathrm{~mL} / \mathrm{min}$ at $623 \mathrm{~K}$ (ramping rate: $0.0333 \mathrm{~K} / \mathrm{s}$ ) for $2 \mathrm{~h}$ and subsequently reduced under a $9 \% \mathrm{H}_{2} / \mathrm{N}_{2}$ flow of $300 \mathrm{~mL} / \mathrm{min}$ at $623 \mathrm{~K}$ (ramping rate: $0.0333 \mathrm{~K} / \mathrm{s}$ ) for $2 \mathrm{~h}$. Before the exposure to ambient air, the sample was passivated under flowing $0.5 \% \mathrm{O}_{2} / \mathrm{N}_{2}(100 \mathrm{~mL} / \mathrm{min})$ for $1 \mathrm{~h}$ at $298 \mathrm{~K}$.

$\mathrm{Ru} / \mathrm{SiO}_{2}$ was prepared with the method reported by Regalbuto. ${ }^{[1]}$ In a typical synthesis, an aqueous solution of $\mathrm{Ru}\left(\mathrm{NH}_{3}\right)_{6} \mathrm{Cl}_{3}(0.01 \mathrm{M})$ was first prepared with a $\mathrm{pH}$ at $\sim 9$. $\mathrm{SiO}_{2}$ (with a point of zero charge $(\mathrm{PZC})$ at $\sim 4$ ) was stepwise added into the solution. After stirring for $4 \mathrm{~h}$, the solids were filtered and washed with deionized water to remove chloride ions. Finally, the obtained solid was dried, treated, and reduced with the same processes as Ru/ZSM-5-IP. 


\section{Synthesis of bifunctional catalysts (Ru@H-ZSM-5, Ru/H-ZSM-5-HT, and Ru/H-}

\section{ZSM-5-IP)}

Ru@ZSM-5, Ru/ZSM-5-HT, and Ru/ZSM-5-IP zeolites were ion-exchanged with 1 mol/L ammonium chloride $\left(\mathrm{NH}_{4} \mathrm{Cl}, 99\right.$ wt.\%, Sinopharm Chemical Reagent Co., Ltd) solution at $360 \mathrm{~K}$ for $2 \mathrm{~h}$, and filtered, washed with water, and then dried at $373 \mathrm{~K}$ over for $\sim 12 \mathrm{~h}$, followed by calcinations at $673 \mathrm{~K}$ for $6 \mathrm{~h}$. The ion-exchange has been carried out for twice and reduced by $10 \% \mathrm{H}_{2} / \mathrm{N}_{2}$ and passivated by $0.5 \% \mathrm{O}_{2} / \mathrm{N}_{2}$ to obtain the H-type samples.

\section{Material Characterization}

Powder X-ray diffraction (XRD) patterns of zeolite samples were measured by a Bruker D8 Advance diffractometer, with $\mathrm{Cu}$ Ka radiation $(40 \mathrm{kV}, 40 \mathrm{~mA})$.

The $\mathrm{Si} / \mathrm{Al}$ ratio and $\mathrm{Ru}$ metal loading in zeolite sample was analysed by inductively coupled plasma plasma-atomic emission spectroscopy (ICP-AES) using an IRIS Advantage spectrometer.

The scanning electron microscope (SEM) and the transmission electron microscope (TEM) were carried to measure the morphology and crystal size of the zeolite samples on a FEI Quanta $200 \mathrm{~F}$ and a JEM 2100 at $200 \mathrm{kV}$, respectively. For the TEM measurement, the zeolite samples were dropped on to the copper grid with a Lacey 
carbon support carbon after dispersing zeolite samples in ethanol by 10 min ultrasonic treatment.

Scanning transmission electron microscopy (STEM) images were obtained with a JEOL JEM-2100F microscope operated at $200 \mathrm{kV}$. Energy dispersive X-ray spectra (EDX-mapping) were collected with a JEOL Oxford X-MaxN $80 \mathrm{~T}$ silicon drift detector, by rastering the beam over the target zone. Aberration-corrected scanning transmission electron microscopy (AC-STEM) in the high angle annular dark field mode (AC-HAADF-STEM) were acquired by using an JEOL JEM ARM-200F STEM operating at $200 \mathrm{kV}$, located in the electron Physical Sciences Imaging Centre at Dalian Institute of Chemical Physics.

The textural properties of the zeolites were measured by the $\mathrm{N}_{2}$-sorption at $77 \mathrm{~K}$. Before sorption measurements, all samples were pre-treated by vacuum degassing at $573 \mathrm{~K}$ for $12 \mathrm{~h}$ to remove water. The measurement was carried out on a Micromeritics ASAP 2020. The Brunauer-Emmett-Teller (BET) equation was used to calculate the specific surface area (denoted as $\mathrm{S}_{\mathrm{BET}}$ ) of zeolite sample by the at relative pressure $\mathrm{P} / \mathrm{P}_{0}$ values below 0.2 .

The dispersion of $\mathrm{Ru}$ crystallites was measured using hydrogen chemisorption (Micromeritics ASAP 2020) at 5.0 50 kPa. ${ }^{33}$ Samples were first treated in pure $\mathrm{H}_{2}$ for $1 \mathrm{~h}$ at $573 \mathrm{~K}(0.0333 \mathrm{~K} / \mathrm{s})$ and then in a dynamic vacuum for $1 \mathrm{~h}$ at $573 \mathrm{~K}$. Ru metal dispersions were calculated by assuming $\mathrm{H} / \mathrm{Ru}_{\mathrm{s}}=2$. Temperature-programmed 
desorption of ammonia ( $\mathrm{NH}_{3}$-TPD) was measured on a Huasi DAS-7000 chemisorption unit. For a typical measurement, $0.10 \mathrm{~g}$ of zeolite samples $(0.250-0.425 \mathrm{~mm})$ were firstly treated at $773 \mathrm{~K}$ with flowing $\mathrm{N}_{2}$ gas stream $\left(30 \mathrm{~mL} \mathrm{~min}{ }^{-1}\right)$ for $1 \mathrm{~h}$ to remove water and then cooled to $373 \mathrm{~K}$ under flowing $\mathrm{N}_{2}$ gas. Subsequently, anhydrous $\mathrm{NH}_{3}$ stream with $30 \mathrm{~mL} / \mathrm{min}$ flowing rate was introduced to replace $\mathrm{N}_{2}$ gas and kept for 30 min at $373 \mathrm{~K}$. After the adsorption of $\mathrm{NH}_{3}$ gas stream, the $\mathrm{N}_{2}$ gas with $20 \mathrm{~mL} \mathrm{~min}{ }^{-1}$ flowing rate was induced to remove excess $\mathrm{NH}_{3}$. Finally, the $\mathrm{NH}_{3}$-TPD was carried out by increasing the desorption temperature from $373 \mathrm{~K}$ to $873 \mathrm{~K}$ with a ramping rate at $10 \mathrm{~K} / \mathrm{min}$. The desorption amount of the $\mathrm{NH}_{3}$ was determined simultaneously by the thermal conductivity detector (TCD).

The Fourier transform infrared (FT-IR) spectra of pyridine adsorption were tested on a Bruker Tensor II equipped with a liquid-nitrogen cooled mercury-cadmium-telluride (MCT) detector. Prior to the measurement, the samples were pressed into wafers and then activated at $623 \mathrm{~K}$ for $1 \mathrm{~h}$ under a vacuum of $1 \times 10^{-2} \mathrm{~Pa}$. When the temperature dropped to $373 \mathrm{~K}$, pyridine adsorption was started and maintained for $30 \mathrm{~min}$, then pyridine was desorbed when the temperature increased, and the spectra were recorded at $473 \mathrm{~K}$.

${ }^{27} \mathrm{Al}$ magic angel spinning (MAS) nuclear magnetic resonance (NMR) measurements were performed on a Bruker Avance III 400WB spectrometer with magnetic field strength of $9.39 \mathrm{~T}(400 \mathrm{MHz})$ at resonance frequencies of $104.3 \mathrm{MHz}$ for ${ }^{27} \mathrm{Al}$. Magic 
angle spinning at $10 \mathrm{kHz}$ was employed using $4 \mathrm{~mm}$ probe. A recycle delay of $0.1 \mathrm{~s}$ was used, and the excitation pulse length was $1.0 \mu$ s (3000 scans). All samples were weighed to enable quantitative measurements.

FT-IR of CO adsorption were conducted on a Bruker Tensor II equipped with a liquid-nitrogen cooled mercury-cadmium-telluride (MCT) detector. Self-supported catalyst wafers were pressed at 2-5 kbar pressure for $10 \mathrm{~s}$. The wafer was placed inside a synchrotron cell with a $\mathrm{CaF}_{2}$ window. The cell was first evacuated to $10^{-3} \mathrm{~Pa}$, and the sample was subsequently degassed at $573 \mathrm{~K}\left(5 \mathrm{~K} \mathrm{~min}^{-1}\right)$ for $1 \mathrm{~h}$. The cell was cooled down to $103 \mathrm{~K}$ with liquid nitrogen and connected to a gas chamber that permitted adjustment of the pressure of $\mathrm{CO}$ injected into the cell. $\mathrm{CO}$ adsorption was studied at $103 \mathrm{~K}$ at stepwise increasing pressures from 20 to $300 \mathrm{~Pa}$. Each spectrum consisting of 32 scans was recorded at a resolution of $4 \mathrm{~cm}^{-1}$.

Temperature-programmed reduction of hydrogen $\left(\mathrm{H}_{2}\right.$-TPR) experiments were performed on a Micromeritics Auto Chem II 2920 equipped with a MKS Cirrus II Mass detector. About $0.1 \mathrm{~g}$ sample was loaded into a U-shape quartz reactor and heated to $623 \mathrm{~K}$ under an Ar flow of $30 \mathrm{~mL} / \mathrm{min}$ for $1 \mathrm{~h}$ to remove adsorbed species. After cooling to $323 \mathrm{~K}$, the flowing gas was then switched to a $10 \mathrm{vol} . \% \mathrm{H}_{2} / \mathrm{Ar}$ flow, and the catalyst was heated to $973 \mathrm{~K}$ at a ramping rate of $10 \mathrm{~K} / \mathrm{min}$.

\section{Catalytic Tests}


Thermostability tests were performed over Ru@ZSM-5 and Ru/SiO${ }_{2}$ after thermal treatment under a $\mathrm{N}_{2}$ flow of $120 \mathrm{~mL} / \mathrm{min}$ at a set of variated temperatures from 573 to $873 \mathrm{~K} . \mathrm{Ru}$ mean particle diameters $\left(\mathrm{d}_{\text {chem }}\right)$ of the samples after heat treatment were calculated based on the metal dispersions measured by $\mathrm{H}_{2}$ chemisorption.

Hydrogenation tests with toluene and 1,3,5-triisopropylbenzen (TIPB) as the probing molecules were performed to test the encapsulation selectivity of $\mathrm{Ru}$ clusters within Ru@ZSM-5 samples. Prior to hydrogenation rate measurement, catalyst powders were mixed with $\mathrm{SiO}_{2}$ and the mixture was pressed and sieved to obtain 0.18-0.25 mm aggregates. A portion of these diluted aggregates (containing 1.0-15.0 mg of original catalyst) was then physically mixed with acid-washed quartz granules of similar particle size to avoid temperature or concentration gradients. Hydrogenation turnover rates for toluene $(111 \mathrm{kPa})$ and 1,3,5-triisopropylbenzen $(6.8 \mathrm{kPa})$ were measured in a continuous flow packed-bed tubular reactor at $423 \mathrm{~K}$ and $2.75 \mathrm{MPa}_{2}$. Catalysts were pretreated in pure $\mathrm{H}_{2}\left(100 \mathrm{~cm}^{3} \mathrm{~g}^{-1} \mathrm{~s}^{-1}\right.$, from ambient temperature to $573 \mathrm{~K}, 0.0333 \mathrm{~K} / \mathrm{s}$, $1 \mathrm{~h}$ hold) before catalytic measurements. The reactant stream contained toluene, TIPB, and $\mathrm{H}_{2}$. Reactant and product concentrations were measured by on-line gas chromatography (GC 7890) using a methyl silicone capillary column (HP-1, Agilent, $25 \mathrm{~m} \times 0.32 \mathrm{~mm} \times 0.52 \mu \mathrm{m})$ connected to a flame ionization detector. Toluene hydrogenation rates are reported here as turnover frequency (TOF) calculated as molar toluene conversion rates per surface metal atom for $\mathrm{Ru}$ metal catalysts and reflect values 
extrapolated to zero residence time to exclude any kinetic effects of reactant depletion or inhibition by products.

Brønsted acid site (BAS) titration experiments were performed by the dehydration of methanol (99.9 \%, Sinopharm Chemical Reagent Co., Ltd) with titration of triphenylphosphine (TPP) at $433 \mathrm{~K}$. The BAS fraction located on the external surface and inside zeolite cavities could be thus determined. The methanol was fed into a flowing $\mathrm{N}_{2}$ gas stream at $363 \mathrm{~K}$ using a syringe pump (KDS 100, KD Scientific). When the methanol conversion dimethyl ether reaction was stable, reactants were switched from methanol to TPP -methanol mixture $\left(1 \times 10^{-4} \mathrm{~mol}\right.$ TPP $)$. Then, the decrease of dehydration rate was recorded by the online gas chromatography (GC 7890) equipped with a flame ionization detector (FID). Compared to the aperture size of ZSM-5 zeolite $(0.55 \mathrm{~nm})$, TPP $(0.84 \mathrm{~nm})$ only titrates the BASs on the external surface. Therefore, the fraction of BAS on external surface (denoted as $\mathrm{F}_{\mathrm{ext}}$ ) was calculated by the decrease of the dehydration rate after the introduction of TPP. The fraction of BAS within zeolite cavities (denoted as $\mathrm{F}_{\text {cav }}$ ) can be obtained as $1-\mathrm{F}_{\text {ext }}$.

Phenol hydrodeoxygenation (HDO) reactions over different catalysts in decalin were carried out in a batch reactor (Beijing Shiji Senlang, Hastelloy, Series E250, $250 \mathrm{~mL}$ ). Typically, the batch reactor was loaded with (3.2 mmol, $0.3 \mathrm{~g})$ phenol $(99.5 \%$, Shanghai Macklin Biochemical Co.,Ltd.) in 80 mL decalin (99\%, Shanghai Macklin Biochemical Co.,Ltd.) and $200 \mathrm{mg}$ catalysts. After loading the mixture, the reactor was firstly flushed 
three times with $\mathrm{N}_{2}$ and charged with $5 \mathrm{MPa} \mathrm{H}_{2}$, and then heated to $423 \mathrm{~K}$ with a slow stirring speed of $200 \mathrm{rpm}$. Once the reaction temperature was achieved, the stirring speed was raised to $1000 \mathrm{rpm}$, which was previously shown to be efficient for avoiding external mass transfer limitations. Analysis of the on-line sampling was conducted at different reaction time. The chemicals were analyzed by a Shimadzu GC-2010 gas chromatograph equipped with a HP-5 capillary column $(30 \mathrm{~m} \times 0.32 \mathrm{~mm} \times 0.25 \mu \mathrm{m})$ and flame ionization detector (FID).

The stability tests were performed at a concentrated substrate solution. Phenol HDO reactions were conducted in a $50 \mathrm{~mL}$ batch autoclave reactor with a quartz lining (AnHui Kemi Machinery Technology Co. LTD). The batch reactor was loaded with phenol (2.13 mmol, $200 \mathrm{mg}$ ) in $10 \mathrm{~mL}$ deionized water and $200 \mathrm{mg}$ catalyst, and reactions were performed at $423 \mathrm{~K}, 5.0 \mathrm{MPa} \mathrm{H}_{2}$. The first run was performed with a fresh catalyst. After the reaction, the catalyst was separated via filtration, washed with water, and dried overnight. Finally, the catalyst was transferred back to the reactor and a new catalytic run was performed with the addition of a new batch of substrate under standard reaction conditions. 


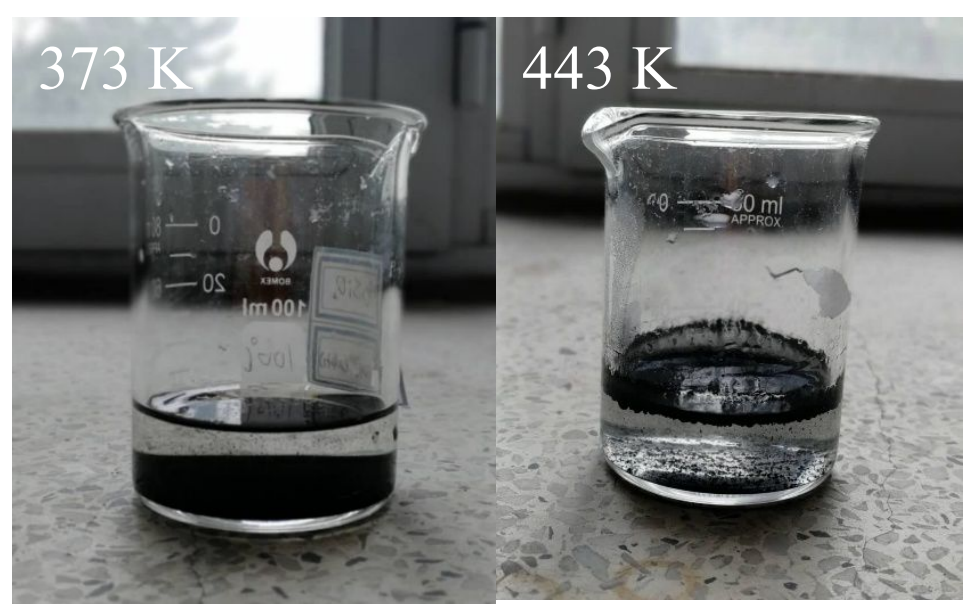

Figure $\mathrm{S} 1$. Stability of $\mathrm{RuCl}_{3}$ precursors in alkaline sodium aluminate solution.

The solutions have the same $\mathrm{pH}$ value and composition as the synthesis gels for corresponding ZSM-5 zeolite except the absence of $\mathrm{SiO}_{2}$ (addition of $\mathrm{SiO}_{2}$ forms turbid gel and make it difficult to investigate the metal precipitation behaviors). $\mathrm{RuCl}_{3}$ precipitate as bulk metal oxides in the high $\mathrm{pH}$ and temperature conditions favoring fast nucleation and crystallization of MFI ( $\sim 6 \mathrm{~h}$ at $373 \mathrm{~K}$ and $\sim 3 \mathrm{~h}$ at $473 \mathrm{~K})$. 


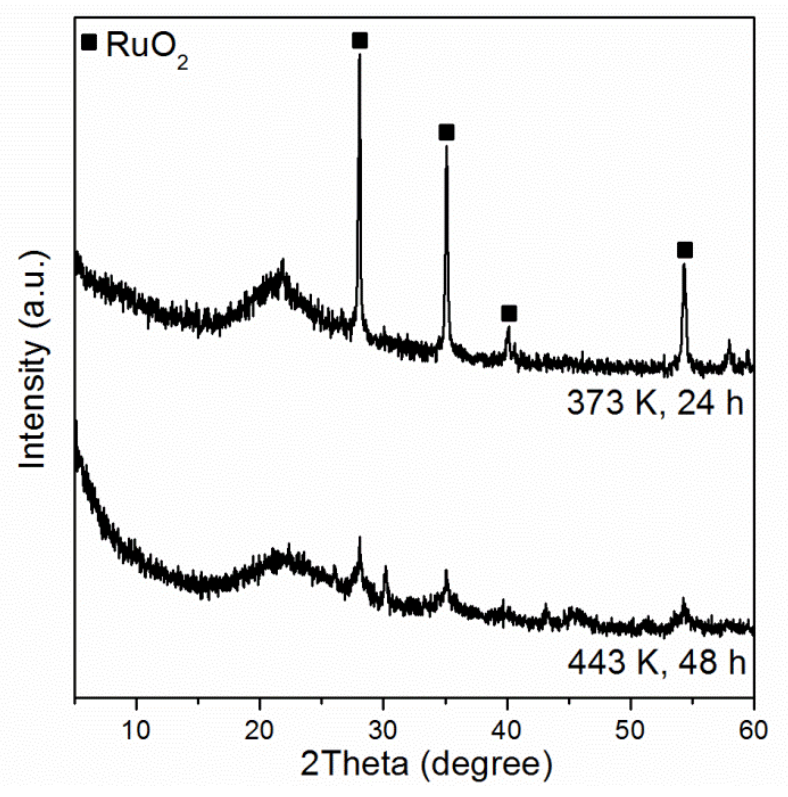

Figure S2. XRD patterns of the $\mathrm{RuCl}_{3}$ precipitates at different hydrothermal synthesis conditions.

Figure $\mathrm{S} 2$ shows the XRD patterns of the precipitates of $\mathrm{RuCl}_{3}$ in alkaline sodium aluminate solution with the same $\mathrm{pH}$ value and composition as the synthesis gels for corresponding ZSM-5 zeolite except the absence of $\mathrm{SiO}_{2}$. Clearly, both samples show the typical diffraction peaks corresponding to $\mathrm{RuO}_{2}$ (JCPDS No.: 1-073-1469), indicating $\mathrm{RuCl}_{3}$ precursors are unstable under the high $\mathrm{pH}$ and temperature conditions. 

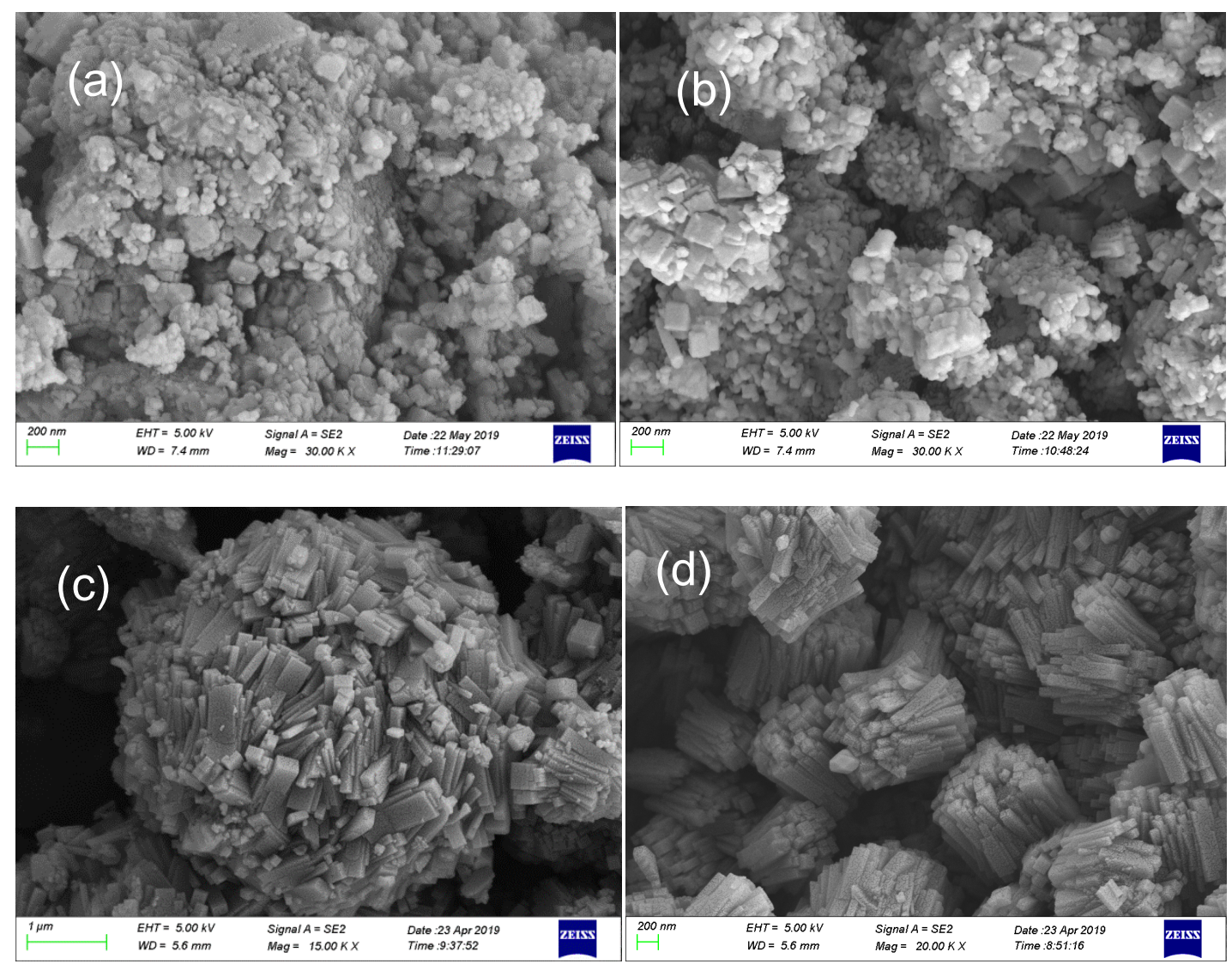

Figure S3. SEM images of (a) ZSM-5 prepared by hydrothermal synthesis, (b) Ru/ZSM5-IP prepared by the impregnation, (c) Ru/ZSM-5-HT prepared by the one-step hydrothermal synthesis and (d) Ru@ZSM-5 prepared by the two-step in-situ hydrothermal synthesis.

The SEM images of all as-prepared zeolite samples are shown in Figure S3. All samples show the aggregates of zeolite crystal with different crystal morphology. Clearly, the introduction of $\mathrm{RuCl}_{3}$ via the impregnation method dose not substantially change the zeolite morphology since the ZSM-5 and Ru/ZSM-5-IP have the similar morphology with the cube crystal size of 50 100 nm. While the crystal morphology of Ru@ZSM-5 and Ru/ZSM-5-HT zeolite changed by forming a cuboid with the size of 
500 1000 nm. Interestingly, the presence of Ru precursors seems to inhibit the growth of the b axis of ZSM-5 crystal in Ru@ZSM-5 and Ru/ZSM-5-HT, resulting in the nanorod crystals. These indicate that the influence of $\mathrm{Ru}$ cations on the crystallization of ZSM-5 zeolites via in-situ hydrothermal synthesis. 

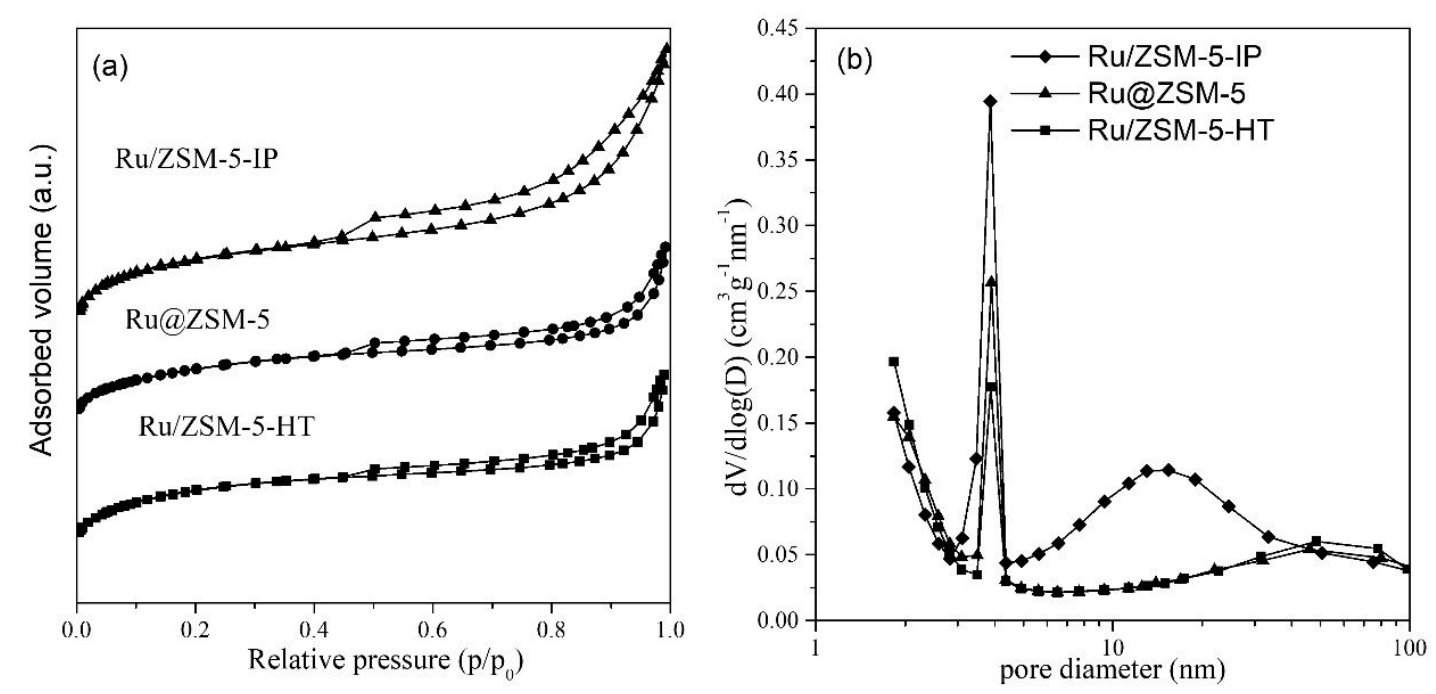

Figure S4. $\mathrm{N}_{2}$ adsorption-desorption isotherms (a) and pore size distribution curves (b) of different Ru-containing ZSM-5 zeolites.

Figure S4 shows the nitrogen sorption isotherm and pore size distribution of zeolite samples. The isotherms show that all samples have microporous and mesopores structure. Ru@ZSM-5 and Ru/ZSM-5-HT show similar pore size distribution, while Ru/ZSM-5-IP possess a broad mesopore size distribution. This is agreement with the SEM images, in which the intercrystalline mesopore forms from the aggregation of zeolite crystals in Ru/ZSM-5-IP. 


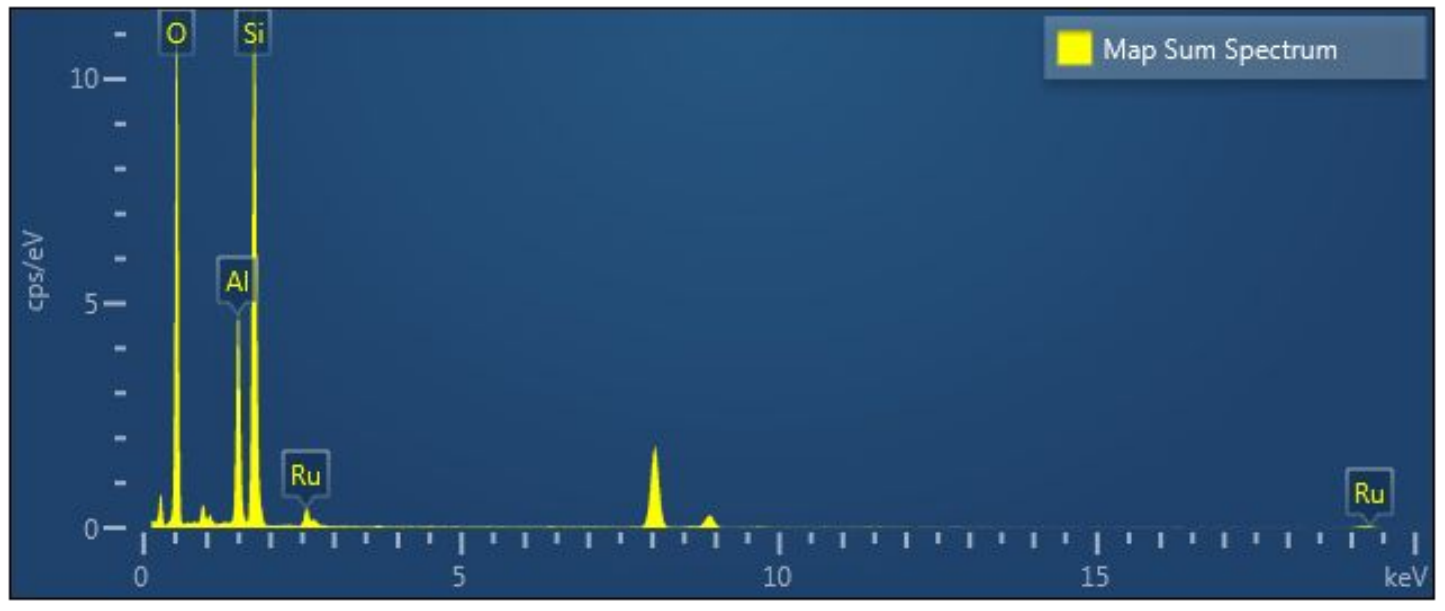

Figure S5. Corresponding EDX spectrum of Ru@ZSM-5. 

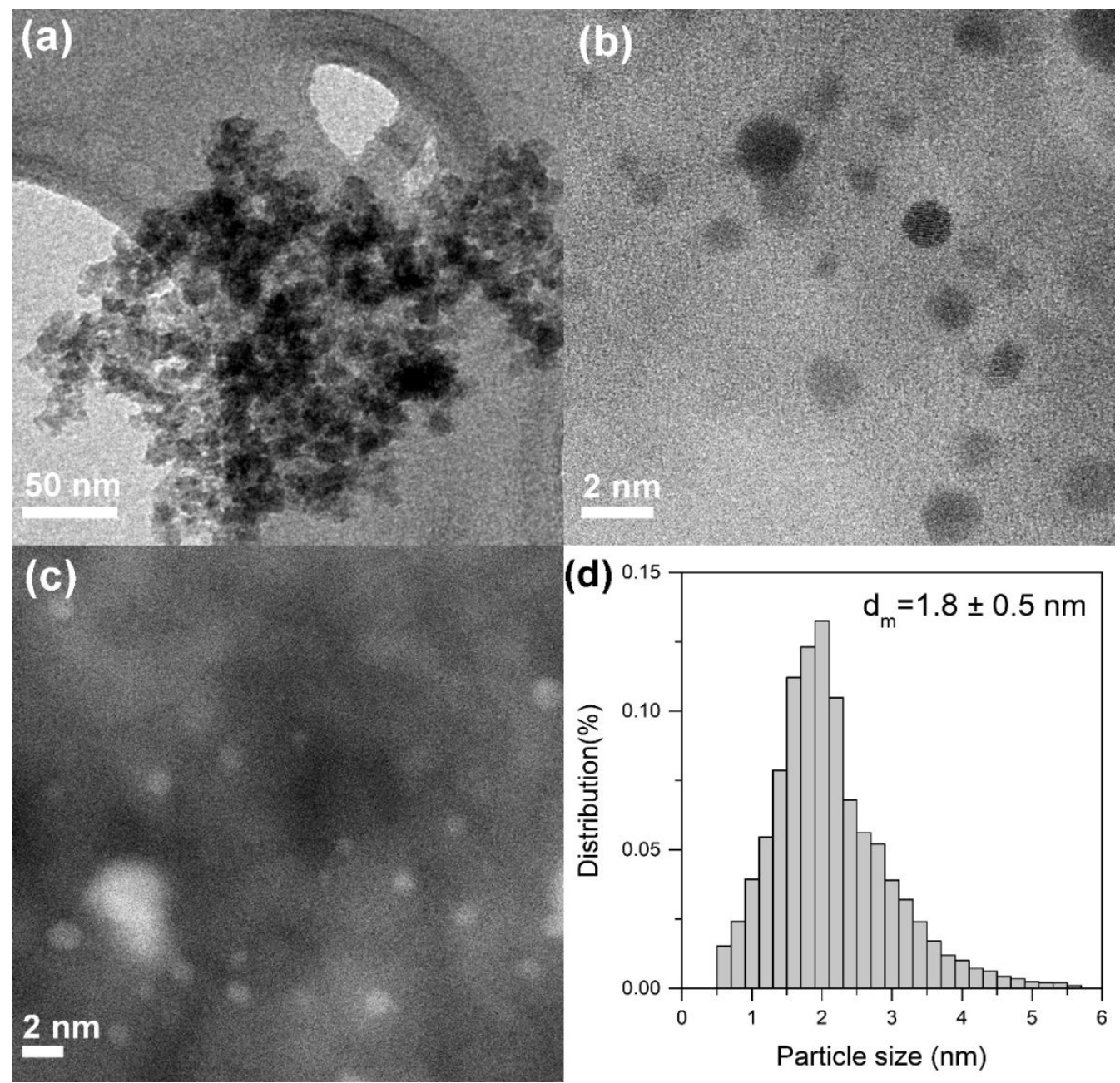

Figure S6. STEM images and the corresponding average diameters of Ru particles $\left(d_{m}\right.$ derived from measurements of over 200 particles) of $\mathrm{Ru} / \mathrm{SiO}_{2}$.

Our synthetic strategy for the $\mathrm{Ru} / \mathrm{SiO}_{2}$ followed with the method reported by Regalbuto ${ }^{[1]}$. Silica placed in solutions of $\mathrm{Ru}\left(\mathrm{NH}_{3}\right)_{6} \mathrm{Cl}_{3}$ at $\mathrm{pH}=\sim 8.5$ above its point of zero charge $(\mathrm{PZC})$ at $3 \sim 4$, would adsorb such cations as $\left[\mathrm{Ru}\left(\mathrm{NH}_{3}\right)_{6}\right]^{3+}$. The metal complex might be considered to deposit onto the surface via strong electrostatic adsorption. The average particle size of $\mathrm{Ru}$ cluster is $\sim 1.8 \mathrm{~nm}$, consistent with the $\mathrm{H}_{2}$ chemisorption results $(1.6 \mathrm{~nm}$, Table 1$)$. 

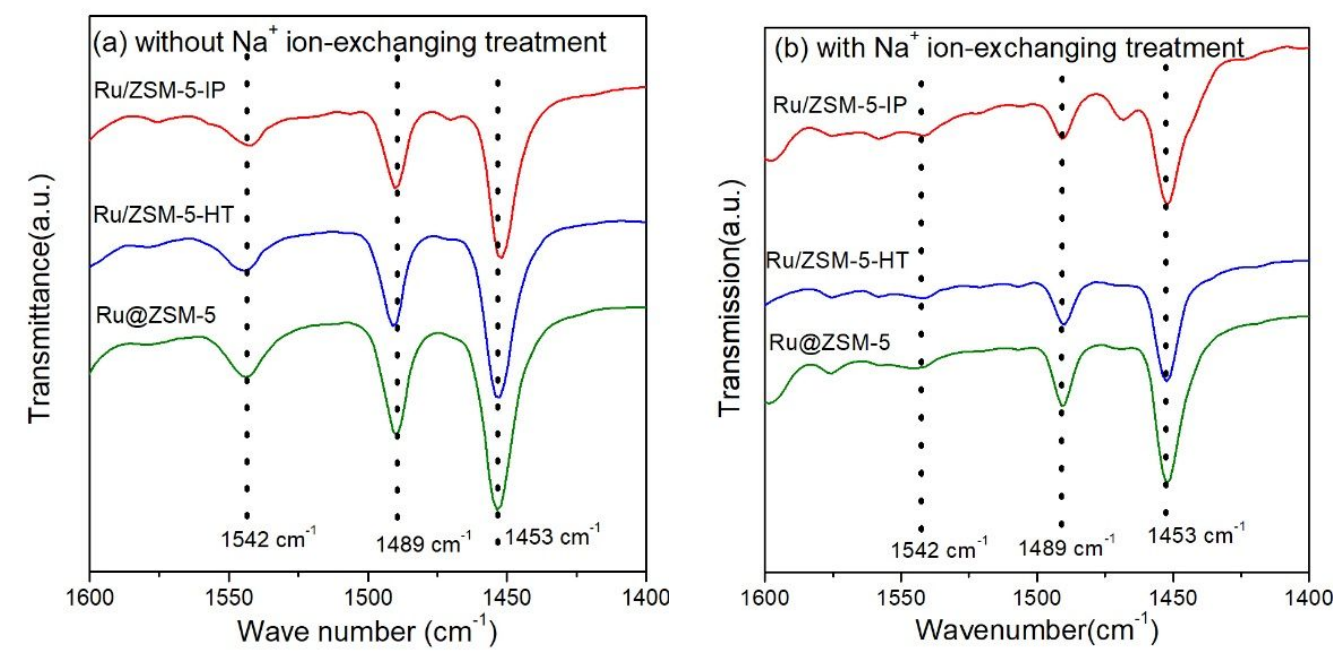

Figure S7. Pyridine-IR spectra of the different Ru-containing ZSM-5 zeolites (a) without and (b) with $\mathrm{Na}^{+}$ion-exchanging treatment.

For $\mathrm{Ru}$-containing zeolite samples, the vibration at $1542 \mathrm{~cm}^{-1}$ corresponds to pyridine interacting with a BAS, and the vibration at $1453 \mathrm{~cm}^{-1}$ is assigned to pyridine interacting with a Lewis acid site. After the $\mathrm{Na}^{+}$ion-exchanging treatment, the $1542 \mathrm{~cm}^{-1}$ vibration disappears for all the three samples completely, indicating the fully ion-exchange of $\mathrm{Na}^{+}$over BAS. 


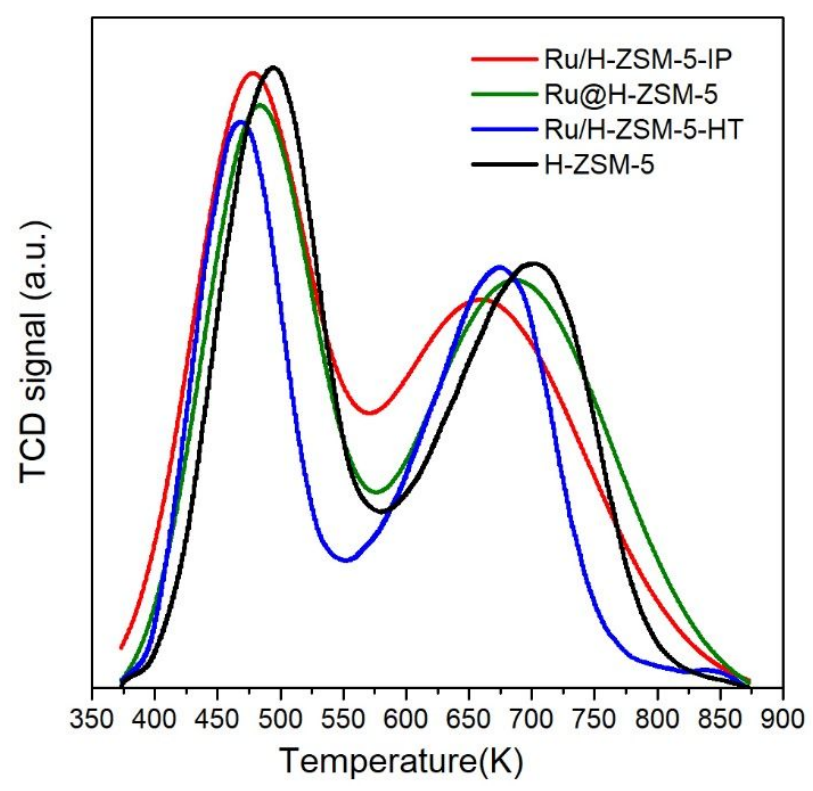

Figure S8. $\mathrm{NH}_{3}$-TPD spectra of the different Ru-containing ZSM-5 zeolite samples.

$\mathrm{NH}_{3}$-TPD was carried out to monitor the acid strength and the amounts of acid sites for the different zeolite samples. The profiles of all samples show the typical course with two unresolved peaks with maxima at around 500 and $700 \mathrm{~K}$ corresponding to ammonia desorbed from the weak and strong acid sites, respectively. Figure S8 shows the $\mathrm{NH}_{3}$-TPD profiles of different zeolite samples. Similar amount of total acid sites (0.45 0.51 mmol/g acid sites) was obtained with all zeolite samples based on the spectra. 


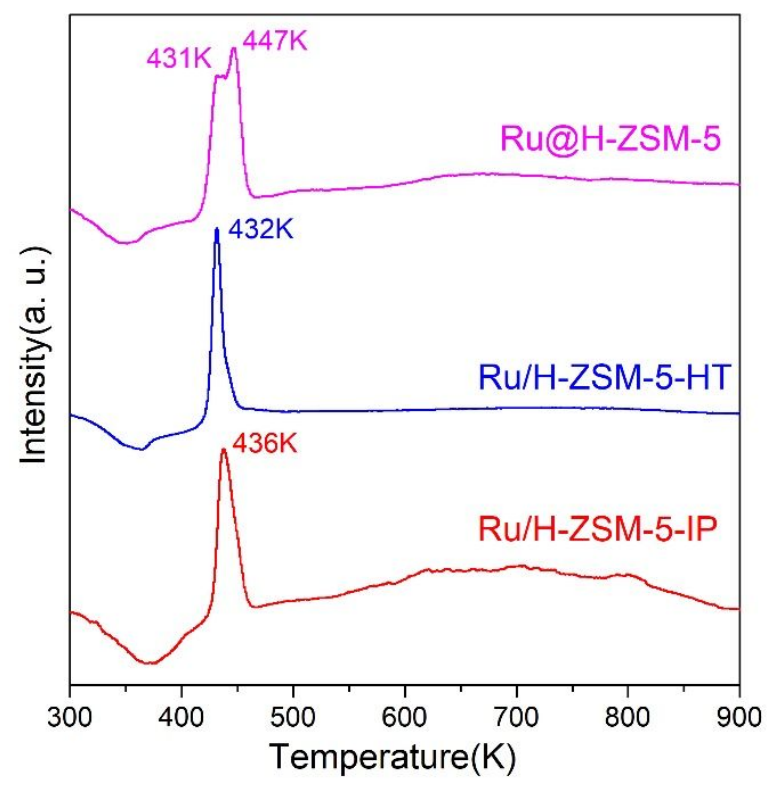

Figure S9. $\mathrm{H}_{2}$-TPR profiles of the Ru@H-ZSM-5, Ru/H-ZSM-5-HT and Ru/H-ZSM5-IP samples.

The $\mathrm{H}_{2}$-TPR profiles of the ZSM-5 supported Ru clusters are shown in Figure S9. The low temperature reduction peak at $\sim 432 \mathrm{~K}$ observed with all the three samples can be attributed to the $\mathrm{Ru}$ species on the external surface of ZSM-5. A higher reduction peak at $447 \mathrm{~K}$ was only shown with Ru@H-ZSM-5, attributed to the Ru species inside the zeolite cavities owing to a stronger metal-support interaction. A slightly larger amount of hydrogen consumption of Ru@ $\mathrm{H}-\mathrm{ZSM}-5$ was observed than that of Ru/HZSM-5-HT and Ru/H-ZSM-5-IP, indicating Ru species possessing a more positive charge in Ru@ZSM-5. 
a. Ru@H-ZSM-5

b. Ru/H-ZSM-5-HT
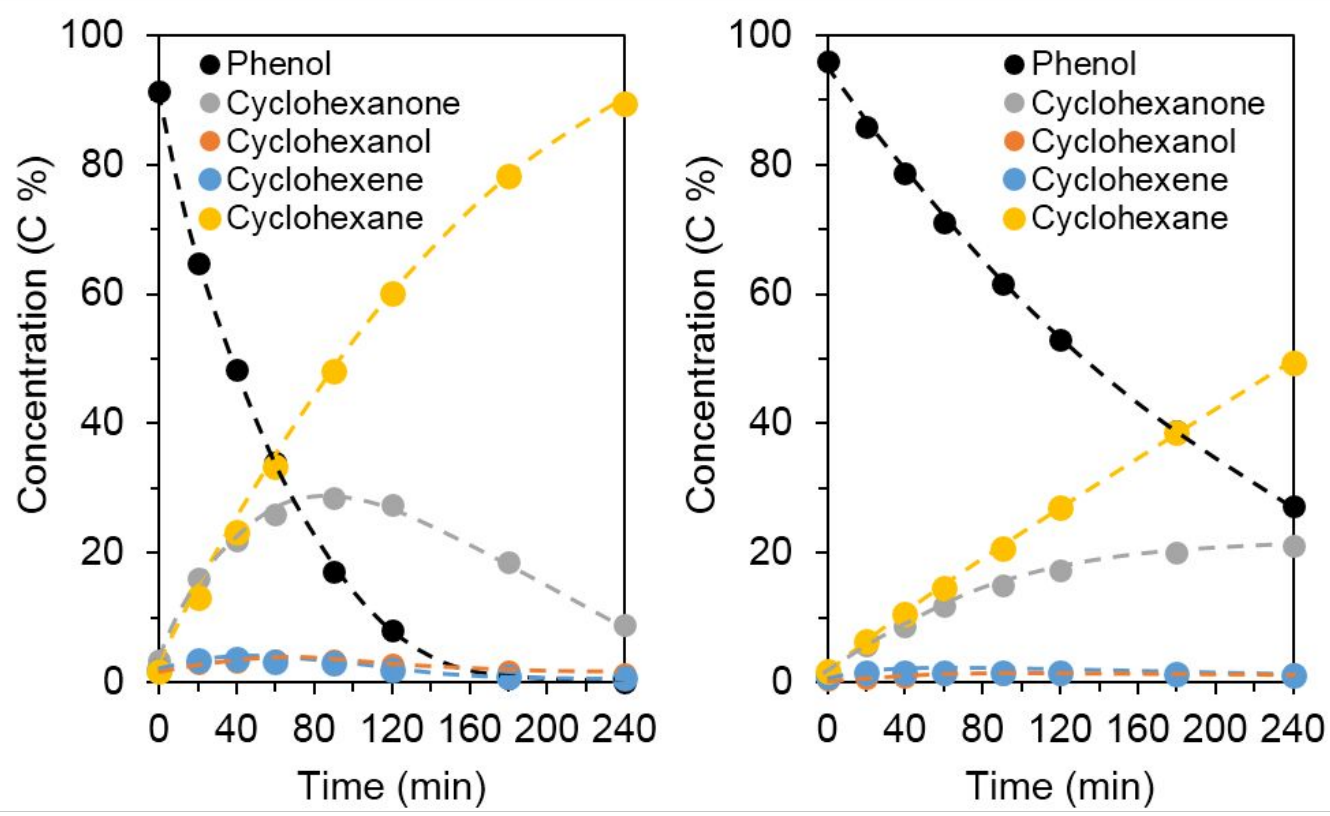

c. Ru/H-ZSM-5-IP

d. $\mathrm{Ru} / \mathrm{SiO}_{2}+\mathrm{H}-\mathrm{ZSM}-5$
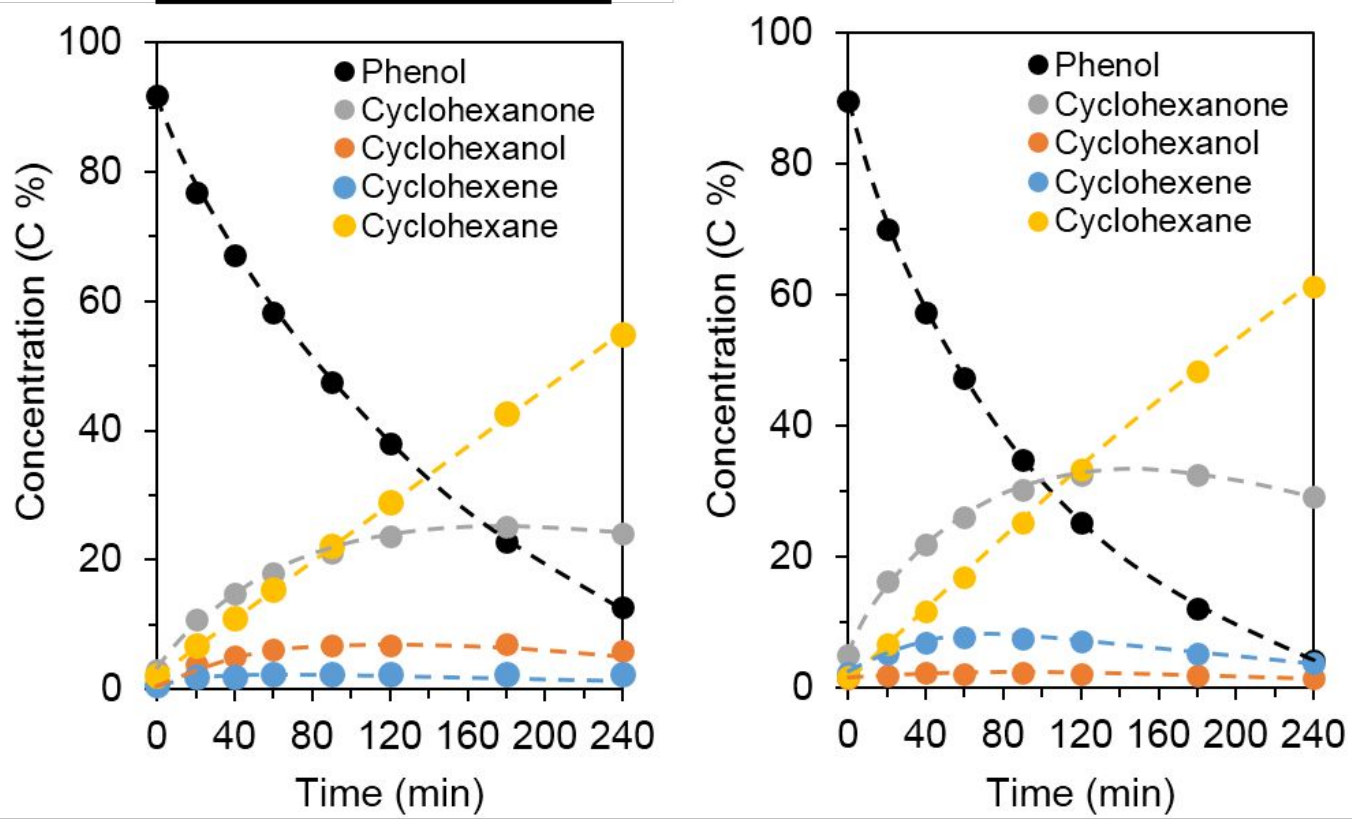

Figure S10. Time profiles of phenol hydrogenation over different bifunctional catalysts in decalin. Reaction conditions: $3.20 \mathrm{mmol}$ phenol, $200 \mathrm{mg}$ catalyst, $80 \mathrm{~mL}$ decalin, $\mathrm{P}_{\mathrm{H} 2}=5.0 \mathrm{MPa}, \mathrm{T}=423 \mathrm{~K}$ 


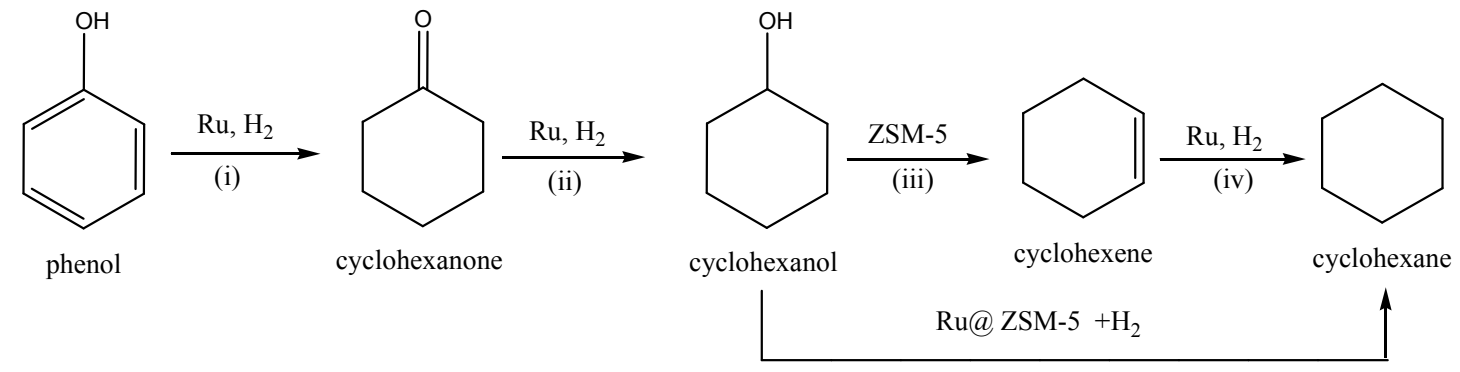

(vi)
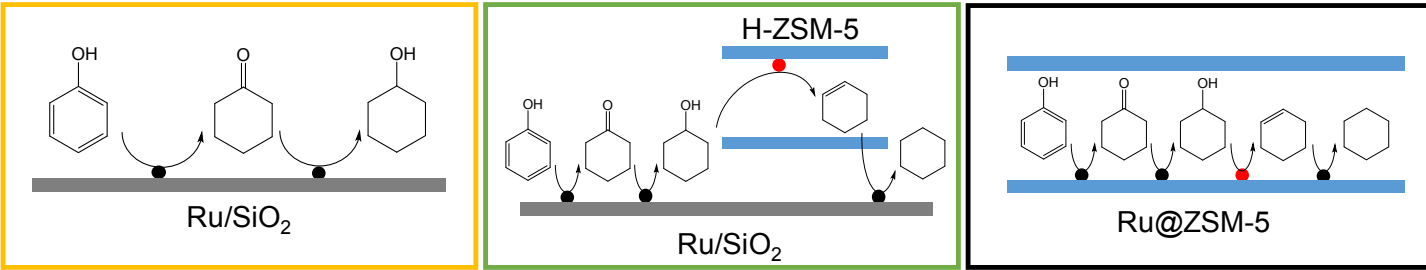

Scheme S1. Proposed reaction pathway for the hydrodeoxygenation of phenol. 
Table S1 Phenol hydrodeoxygenation over different catalysts in water ${ }^{[a]}$

\begin{tabular}{lll}
\hline Sample & $\begin{array}{l}\mathrm{TOF}^{[\mathrm{b}]}\left(\mathrm{mol}_{\text {phenol }} \bullet \mathrm{mol}_{\text {surf- }}{ }^{-1} \bullet \mathrm{S}^{-1}\right) \\
\mathrm{Ru} @ \mathrm{H}-\mathrm{ZSM}-5\end{array}$ & $\begin{array}{l}\text { Productivity of } \\
\text { Cyclohexane }\left(\mathrm{mmol} \cdot \mathrm{g}_{\mathrm{Ru}}{ }^{-}\right. \\
\left.1 \bullet \mathrm{S}^{-1}\right)\end{array}$ \\
$\mathrm{Ru} / \mathrm{H}-Z \mathrm{SM}-5-\mathrm{HT}$ & 0.040 & 0.050 \\
$\mathrm{Ru} / \mathrm{H}-Z \mathrm{SM}-5-\mathrm{IP}$ & 0.021 & 0.032 \\
$\mathrm{Ru} / \mathrm{SiO}_{2}+\mathrm{H}-\mathrm{ZSM}-5$ & 0.021 & 0.031 \\
\hline
\end{tabular}

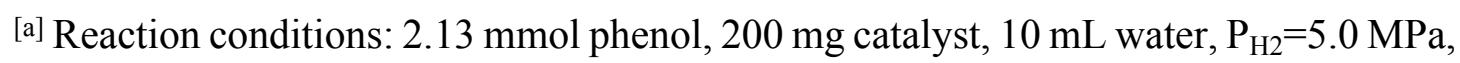
$\mathrm{T}=423 \mathrm{~K}$ and a stirring speed of $1000 \mathrm{rpm}$..

[b] TOF was determined at a low phenol conversion level of $20-30 \%$ 
Table S2. Aqueous-phase dehydration of cyclohexanol over different catalysts. ${ }^{[a]}$

\begin{tabular}{|c|c|c|c|c|c|}
\hline \multirow{2}{*}{ Catalyst } & \multirow{2}{*}{$\begin{array}{l}\text { Reaction } \\
\text { time }(\mathrm{h})\end{array}$} & \multirow{2}{*}{$\begin{array}{l}\text { Conversion } \\
(\%)\end{array}$} & \multicolumn{3}{|c|}{ Selectivity (\%) } \\
\hline & & & Cyclohexene & Cyclohexane & Cyclohexanone \\
\hline $\mathrm{Ru} / \mathrm{SiO}_{2}$ & 2 & 3.5 & 0 & 0 & $\sim 100$ \\
\hline H-ZSM-5 & 2 & 65.1 & 92 & 0 & 8 \\
\hline $\mathrm{Ru} / \mathrm{SiO}_{2}+\mathrm{H}-\mathrm{ZSM}-5$ & 0.1 & 4.5 & 45.0 & 47.9 & 6.2 \\
\hline $\mathrm{Ru} / \mathrm{SiO}_{2}+\mathrm{H}-\mathrm{ZSM}-5$ & 0.5 & 16.2 & 8.1 & 90.5 & 1 \\
\hline $\mathrm{Ru} / \mathrm{SiO}_{2}+\mathrm{H}-\mathrm{ZSM}-5$ & 2 & 83.5 & 0 & $\sim 100$ & 0 \\
\hline Ru@H-ZSM-5 & 0.1 & 7.5 & 12.2 & 86.1 & 0.6 \\
\hline Ru@H-ZSM-5 & 0.5 & 48.2 & 0.2 & 98.7 & 0 \\
\hline Ru@H-ZSM-5 & 2 & 99 & 0 & $\sim 100$ & 0 \\
\hline
\end{tabular}

[a] Reaction conditions: cyclohexanol $(2.0 \mathrm{mmol}, 200 \mathrm{mg})$ and $200 \mathrm{mg}$ catalyst was added to $10 \mathrm{~mL}$ water in the reactor, $423 \mathrm{~K}, 5 \mathrm{MPa} \mathrm{H}_{2}$, and a stirring speed of 1000 rpm.

No cyclohexane was produced with monofunctional catalysts with only metal or acid sites $\left(\mathrm{Ru} / \mathrm{SiO}_{2}\right.$ and $\left.\mathrm{H}-\mathrm{ZSM}-5\right)$. Comparing to $\mathrm{Ru} / \mathrm{SiO}_{2}+\mathrm{H}-\mathrm{ZSM}-5$, $\mathrm{Ru} @ \mathrm{H}-\mathrm{ZSM}-5$ with a closer proximity of metal and acid sites showed a higher cyclohexanol conversion and 
cyclohexane selectivity, indicating that the metal clusters encapsulated inside the zeolite provide the metal-acid intimacy which enhances the catalyst activity as well as the cyclohexane selectivity.

\section{References}

[1] Jiao, L.; Regalbuto, J. R. The synthesis of highly dispersed noble and base metals on silica via strong electrostatic adsorption: I. Amorphous silica, J. Catal. 2008, 260 (2), 329-341. 